\title{
Estudio de la mortalidad postoperatoria al año en pacientes mayores de 65 años
}

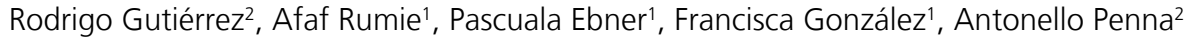

Introducción: La mortalidad intraoperatoria ha disminuido significativamente en las últimas tres décadas, a pesar de la mayor edad y carga de comorbilidades de los pacientes. Sin embargo, no se ha observado lo mismo en la mortalidad postoperatoria a largo plazo, estimándose que la mortalidad al año en adultos mayores es cercana a un $10 \%$. No obstante, no existen reportes en nuestro país. Por ello, es necesario conocer datos nacionales con la finalidad de establecer medidas de intervención.

Objetivo: Determinar la mortalidad durante el primer año postoperatorio de un grupo de pacientes mayores de 65 años en nuestro centro.

Metodología: Tras la aprobación del comité de ética, se obtuvo una muestra aleatoria de 235 pacientes de un total de 2.832 pacientes $\geq 65$ años sometidos a una cirugía que requirió de una anestesia general o regional entre el período de agosto de 2015 a julio de 2016. Este tamaño muestral fue calculado para detectar una incidencia de mortalidad de 10\% $\pm 5 \%$, con un poder de $80 \%$, un error $\alpha$ de 0,05 y una pérdida de $10 \%$. Se registraron los antecedentes demográficos, se calculó el puntaje de Charlson
Comorbidity Index (CCl) y se consignó la mortalidad desde el Registro Civil.

Resultados: Se analizaron 233 pacientes de la muestra, dado que 2 pacientes fueron sometidos sólo a sedación. La edad promedio del grupo fue de 73,1 \pm 6,3 años y la mediana del CCl fue de 4 (rango 2-11). Un $65 \%$ de los pacientes fue sometido a una anestesia general, mientras un 35\% recibió una anestesia regional. La mortalidad a los 30 días fue de 1,3\% y al año fue de 5,6\%. El grupo de pacientes fallecidos se caracterizó por ser estadísticamente más añosos, tener un $\mathrm{CCl}$ mayor y una mayor tasa de complicaciones postoperatorias, no así al comparar las medianas de las duraciones de las cirugías y el tipo de anestesia.

Conclusiones: Se concluye que la mortalidad postoperatoria al año está por debajo de lo reportado. No obstante, la mortalidad aumenta con la edad y las comorbilidades de los pacientes. La menor mortalidad podría ser explicada por una población con menores comorbilidades que los otros estudios. Dado que, en el caso particular de nuestro país, los pacientes con más comorbilidades habitualmente se atienden en el sistema público de salud.

Universidad de Chile. Chile.

Departamento de anestesiología y medicina perioperatoria, Universidad de Chile. Chile. 